\title{
Correlation Between Mechanography and Clinical Parameters at Six Months After Hip Fracture Surgery
}

\author{
Tae Jun Min, $\mathrm{MD}$, $\mathrm{MS}^{1}$, Junmo Cho, $\mathrm{MD}^{1}$, Yong-Chan $\mathrm{Ha}, \mathrm{MD}, \mathrm{PhD}^{2}$, Jae-Young Lim, $\mathrm{MD}, \mathrm{PhD}^{3}$, \\ Si Hyun Kang, MD, PhD ${ }^{1}$, Don-Kyu Kim, MD, $\mathrm{PhD}^{1}$, Kyung Mook Seo, MD, PhD ${ }^{1}$, Jaewon Beom, MD, $\mathrm{PhD}^{1}$
}

Departments of ${ }^{1}$ Physical Medicine and Rehabilitation, ${ }^{2}$ Orthopaedic Surgery, Chung-Ang University Hospital, Chung-Ang University College of Medicine, Seoul; ${ }^{3}$ Department of Rehabilitation Medicine, Seoul National University Bundang Hospital, Seoul National University College of Medicine, Seongnam, Korea

Objective To investigate the correlation between mechanography and clinical parameters in older people at 3 and 6 months after hip fracture surgery.

Methods A longitudinal follow-up study was conducted in university hospitals with 38 patients at 3 months and 29 patients at 6 months after hip fracture surgery. Subjects 65 years and older completed measurements on the Berg Balance Scale (BBS), Functional Ambulation Category (FAC), walking ability by Koval, Korean version of the fatigue, resistance, ambulation, illnesses, and loss of weight (K-FRAIL) scale, and hand grip strength. The Romberg test with center of foot pressure (COP), chair rise test (CRT), and maximal power (W/kg) were conducted using the Leonardo Mechanograph.

Results COP area and pathway length were correlated with BBS at 3 and 6 months. Change in BBS was correlated with change in COP area, but not with change in COP length. COP area and pathway length were correlated with K-FRAIL at 3 months after hip fracture surgery. The same COP variables showed correlations with FAC and walking ability by Koval at 6 months after surgery. Maximal power during CRT had correlation with chair rise time but not with other clinical parameters.

Conclusion The study revealed correlations between mechanography and clinical parameters in older people at 3 and 6 months after hip fracture surgery. Both the clinical assessment and objective test with mechanography may be required for the quantitative and sensitive measurement of postural balance and lower limb muscle power.

Keywords Hip fractures, Postural balance, Dependent ambulation, Muscle strength

\section{Received June 27, 2019; Accepted September 4, 2019}

Corresponding author: Jaewon Beom

Department of Physical Medicine and Rehabilitation, Chung-Ang University Hospital, Chung-Ang University College of Medicine, 102 Heukseok-ro, Dongjak-gu, Seoul 06973, Korea. Tel: +82-2-6299-3176, Fax: +82-2-6299-2064, E-mail: powe5@cau.ac.kr

ORCID: Tae Jun Min (http://orcid.org/0000-0002-9976-3053); Junmo Cho (http://orcid.org/0000-0003-3105-571X); Yong-Chan Ha (http://orcid. org/0000-0002-6249-0581); Jae-Young Lim (http://orcid.org/0000-0002-9454-0344); Si Hyun Kang (http://orcid.org/0000-0003-0205-067X); Don-Kyu Kim (http://orcid.org/0000-0001-8619-830X); Kyung Mook Seo (http://orcid.org/0000-0002-9762-085X); Jaewon Beom (http://orcid.org/0000-00017984-9661).

(c) This is an open-access article distributed under the terms of the Creative Commons Attribution Non-Commercial License (http://creativecommons.org/ licenses/by-nc/4.0) which permits unrestricted noncommercial use, distribution, and reproduction in any medium, provided the original work is properly cited. Copyright ( 2019 by Korean Academy of Rehabilitation Medicine 


\section{INTRODUCTION}

After hip fracture surgery, it is crucial to regain premorbid or pre-fracture physical functions such as walking ability, lower-limb muscle strength, and postural balance. Delay of rehabilitation, cognitive dysfunction, old age, and trochanteric fracture type can be risk factors associated with post-fracture functional recovery [1]. Thus, the periodic and sensitive assessment of physical function is essential. The Berg Balance Scale (BBS) is a representative performance-oriented measure of balance, particularly used in older adults [2], and could be used for a sensitive evaluation of functional improvement in patients surgically treated for hip fracture [3]. When the test is performed periodically after hip fracture surgery, the change in BBS scores reflects the degree of functional recovery. However, it takes time to measure all 14 items, and it is not a completely quantitative test with a score of 0-4 for each item.

Another novel method is mechanography using a force sensor. On the force platform, the center of foot pressure (COP) and trajectory of COP are automatically calculated during double limb support standing. Various COP-related parameters such as the COP area and length are measured [4]. In a previous study, the reliability and validity of measuring balance using COP-related parameter have been demonstrated in older adults [5]. It has also been used to evaluate patients having problems with balance, those who are post-stroke, or those with Parkinson disease $[6,7]$. Therefore, it would be useful to demonstrate the utility of mechanography in the evaluation of functional improvement in patients after hip fracture surgery.

Muscle weakness in the elderly is closely correlated with frailty. Fried et al. have defined frailty as a condition in which three out of five phenotypic criteria indicating compromised energetics-low grip strength, low energy, slowed waking speed, low physical activity, and/or unintentional weight loss-are met [8]. To evaluate frailty more simply, Morley et al. have suggested measurements on a fatigue, resistance, ambulation, illnesses, and loss of weight (FRAIL) scale, which includes a simple 5-item questionnaire [9]. The Korean version of the FRAIL (KFRAIL) scale can be applied to Koreans [10]. The muscle strength of the lower limbs can also be measured quantitatively using mechanography from the force platform. Lower-limb muscle power is measured during vertical jump or chair rise on a force platform $[11,12]$. Since the vertical jump test would be challenging due to pain and a risk of fall for patients after hip fracture surgery, measuring maximal power during chair rise is more feasible.

We investigated the relationship between COP variables and BBS as well as other ambulation-related parameters, and the relationship between maximal power during the chair rise test (CRT) from mechanography, hand grip strength (HGS), and K-FRAIL scale after hip fracture surgery.

\section{MATERIALS AND METHODS}

\section{Subjects}

A longitudinal prospective study was conducted in university hospitals on patients with hip fractures from September 2016 to August 2018. We analyzed subjects aged 65 years and older who had completed measurements on the BBS and K-FRAIL scales, Functional Ambulation Category (FAC), walking ability by Koval [13], HGS, Romberg test, and CRT at 3 and 6 months after hip fracture surgery. Patients with severe cognitive impairment to the extent that they could not perform simple instructions or those with severe lower extremity weakness caused by other neurological diseases were excluded. Thirtyeight patients at 3 months after hip fracture surgery and 29 patients at 6 months after hip fracture surgery were evaluated (Fig. 1). Informed consent was received from all participants, and the study protocol was approved by the Institutional Review Board of Chung-Ang University Hospital (No. C2016117(1860)), Seoul National University Bundang Hospital (No. B-1603/337-002), and Chungnam National University Hospital (No. 2016-07-018).

\section{Mechanography measurement}

Patients were evaluated with the Romberg test and CRT using the foot pressure platform, Leonardo Mechanograph (Novotec Medical GmbH, Pforzheim, Germany) at 3 and 6 months after hip fracture surgery. For the Romberg test, patients were asked to stand upright on the force platforms with their feet together and eyes open for 10 seconds (Fig. 2A). COP during the Romberg test was measured using the mechanograph. COP length represents total body sway trajectory ( $\mathrm{mm}$ ) during the Romberg test. The mechanograph also records the area $\left(\mathrm{mm}^{2}\right)$ inside the trajectory curve. Both the COP area and length 


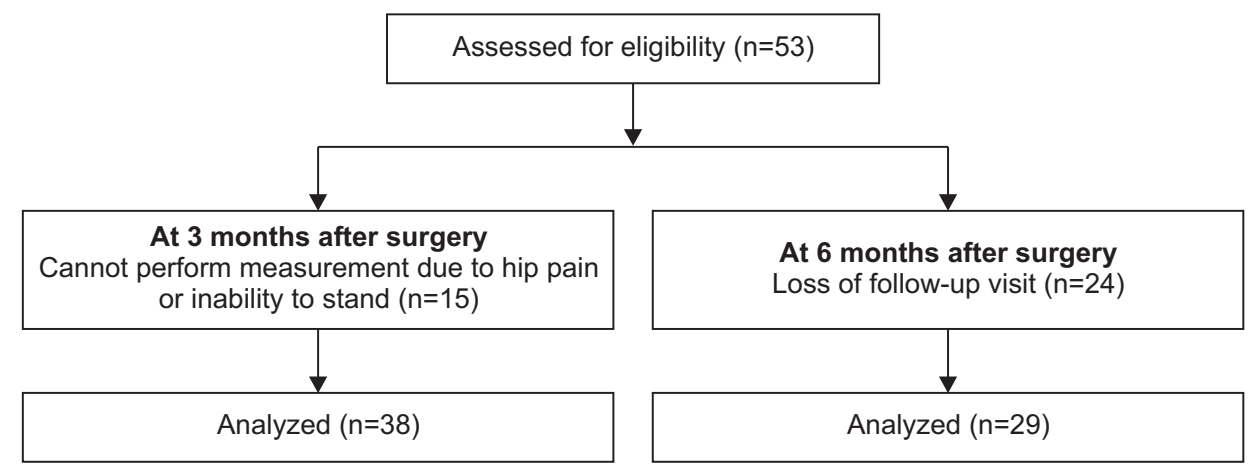

Fig. 1. Schematic diagram for the study process.
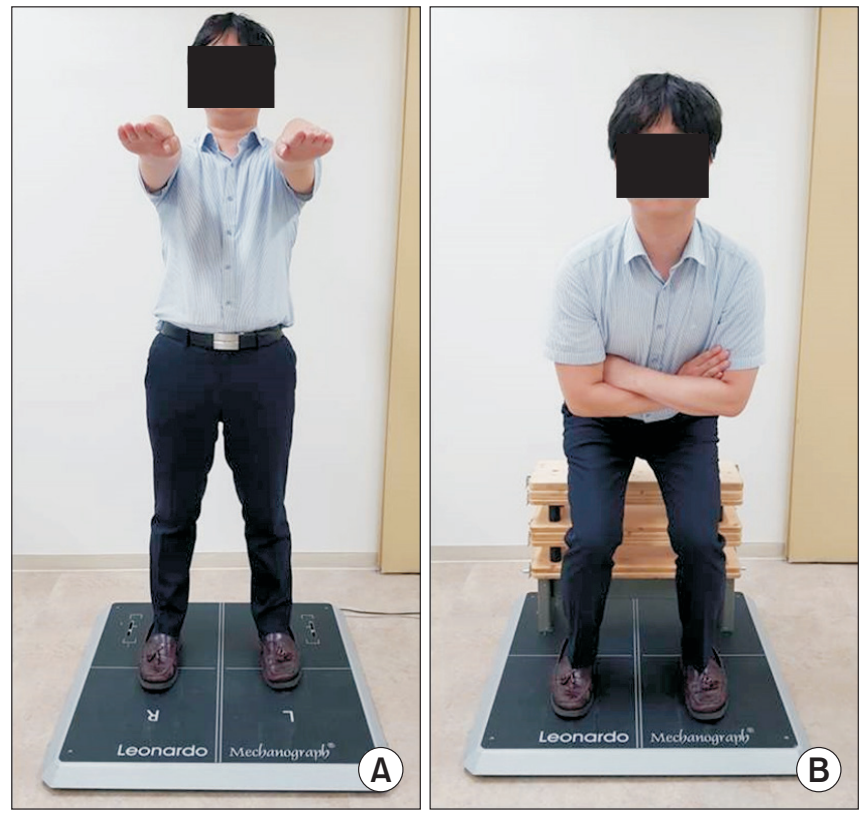

Fig. 2. Romberg test (A) and chair rise test (B) by the Leonardo Mechanograph (Novotec Medical GmbH, Pforzheim, Germany).

are quantitative parameters of stability, in that increased COP area or length represents decreased stability. For CRT, patients conducted 5 repetitions of sit-to-stand from the chair (Fig. 2B). The Mechanograph measured maximum power $(\mathrm{W} / \mathrm{kg})$ and time (s) during chair rise. The exemplar results of the Romberg test and CRT are presented (Figs. 3, 4).

\section{Clinical assessments}

BBS is a 14-item scale designed to measure balance by assessing the performance of functional tasks. Each task is given a score of 0 (unable) to 4 (independent). FAC consists of a 6-point scale that assesses functional ambulation by determining how much support the patient needs when walking. Walking ability by Koval represents ambulatory ability defined as seven stages: (1) independent community ambulation, (2) community ambulation with a cane, (3) community ambulation with a walker or crutches, (4) independent household ambulation, (5) household ambulation with a cane, (6) household ambulation with a walker or crutches, and (7) non-functional ambulation. K-FRAIL is the Korean version of the FRAIL (fatigue, resistance, ambulation, illnesses, and loss of weight) scale, which is a screening tool for determining the frailty status using a simple 5-item questionnaire. To measure HGS, patients are instructed to squeeze a handle of dynamometer as hard as possible for 3 seconds seated in a chair without arm rest with their shoulders adducted and neutrally rotated, elbows flexed at $90^{\circ}$, and with neutral position of the wrists, and the maximum isometric force is recorded.

\section{Statistical analysis}

The IBM Social Science Statistics version 21.0 Statistical Package (IBM Corp., Armonk, NY, USA) was used to analyze data. The level of statistical significance was set at $\mathrm{p}<0.05$. Pearson correlation coefficients were calculated for comparisons of BBS, FAC, walking ability by Koval, K-FRAIL, HGS, COP during the Romberg test, and maximal power $(\mathrm{W} / \mathrm{kg})$ during CRT in mechanography at 3 and 6 months after hip fracture surgery. We also compared changes in BBS at 3 and 6 months after surgery and changes in mechanography using Spearman correlation coefficients.

\section{RESULTS}

The characteristics of subjects included at 3 and 6 months after hip fracture surgery are presented in Table 1. COP 


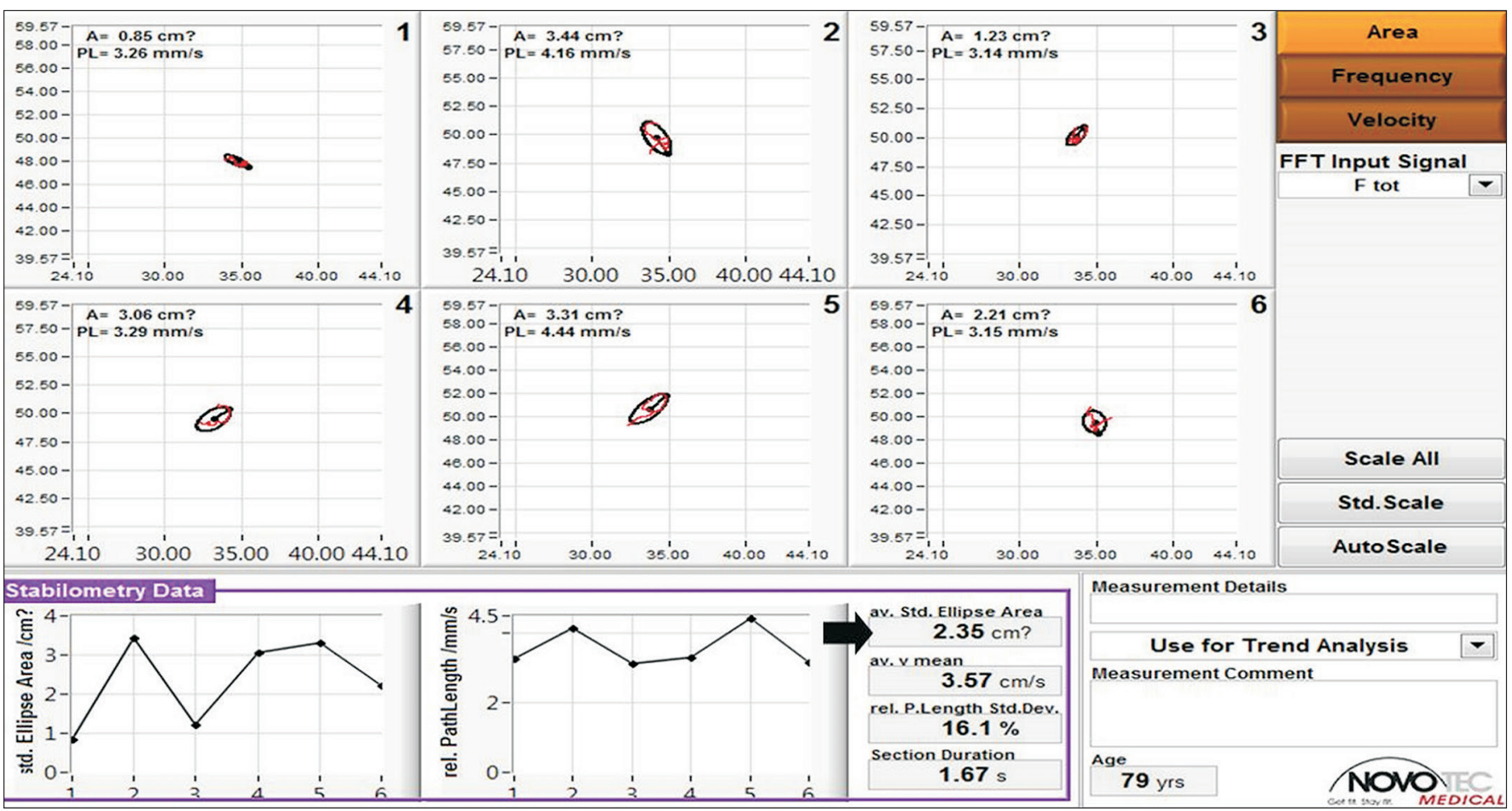

Fig. 3. Exemplar results of the Romberg test in mechanography in a 79-year-old female with left femur neck fracture. Ellipse area (black arrow) was used for statistical analysis.

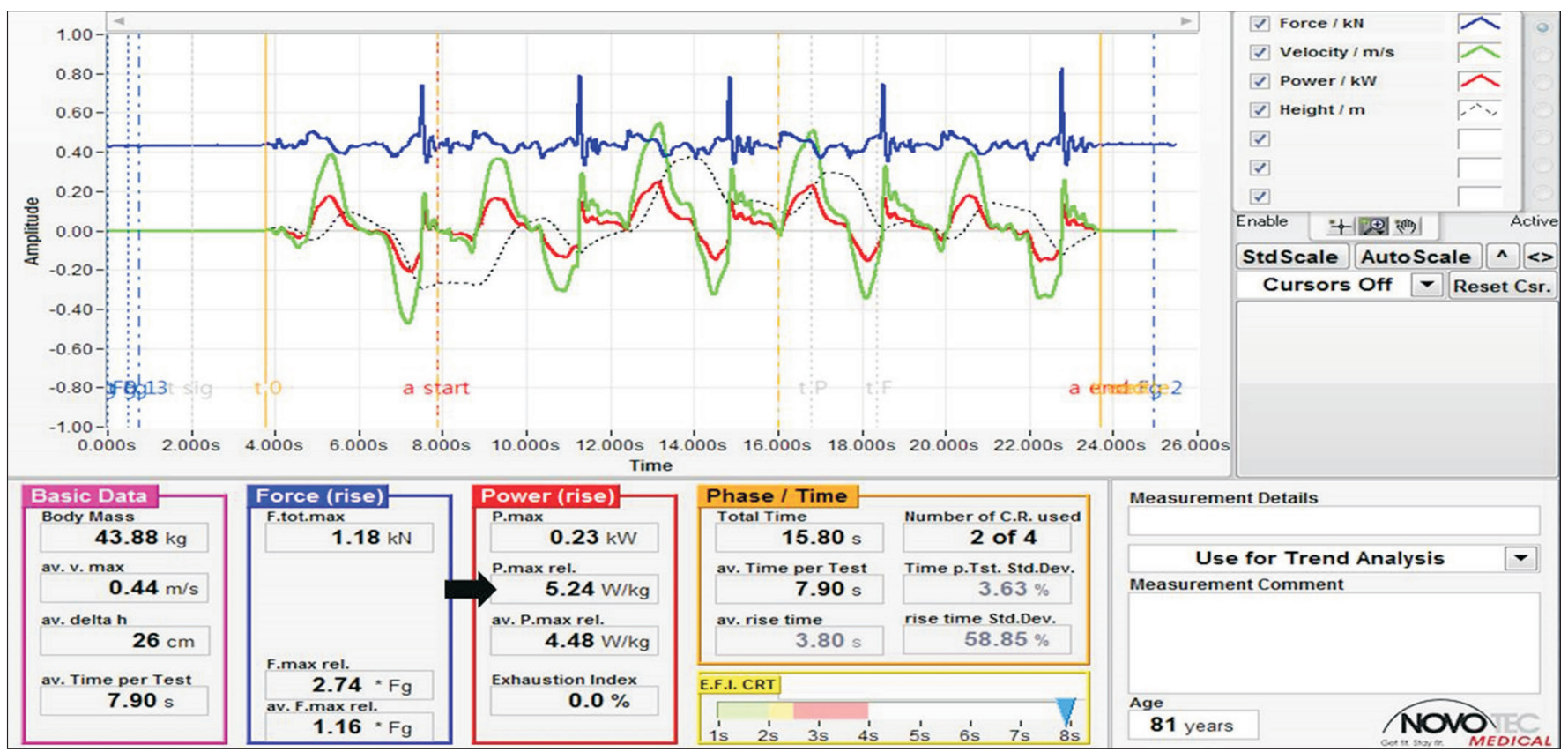

Fig. 4. Exemplar results of maximal power during the chair rise test in mechanography in an 81-year-old female with right femur neck fracture. Peak maximal power (black arrow) was used for statistical analysis. The center of foot pressure length represents the total body sway trajectory $(\mathrm{mm})$ during the Romberg test. The mechanograph also records the area $\left(\mathrm{mm}^{2}\right)$ inside the trajectory curve. 
Tae Jun Min, et al.

Table 1. Patients' demographics at 3 and 6 months after hip fracture surgery

\begin{tabular}{|c|c|c|}
\hline Characteristic & $\begin{array}{l}3 \text { months } \\
(n=38)\end{array}$ & $\begin{array}{c}6 \text { months } \\
(n=29)\end{array}$ \\
\hline Age (yr) & $79(68-92)$ & $83(66-92)$ \\
\hline \multicolumn{3}{|l|}{ Sex } \\
\hline Male & 8 & 7 \\
\hline Female & 30 & 22 \\
\hline \multicolumn{3}{|l|}{ Fracture side } \\
\hline Right & 18 & 12 \\
\hline Left & 20 & 17 \\
\hline \multicolumn{3}{|l|}{ Fracture location } \\
\hline Femur neck & 15 & 14 \\
\hline Intertrochanteric & 20 & 14 \\
\hline Subtrochanteric & 3 & 1 \\
\hline \multicolumn{3}{|l|}{ Operation type } \\
\hline Hemiarthroplasty & 23 & 15 \\
\hline Internal fixation & 15 & 14 \\
\hline Height $(\mathrm{cm})$ & $\begin{array}{c}155.5 \\
(142.0-174.0)\end{array}$ & $\begin{array}{c}158.0 \\
(143.0-174.0)\end{array}$ \\
\hline Weight (kg) & $\begin{array}{c}56.4 \\
(37.0-70.2)\end{array}$ & $\begin{array}{c}53.2 \\
(37.0-76.0)\end{array}$ \\
\hline BBS & $43(13-54)$ & $44(23-55)$ \\
\hline FAC & $4(2-6)$ & $4(3-5)$ \\
\hline Walking ability by Koval & $2(1-6)$ & $2(1-6)$ \\
\hline K-FRAIL & $1(0-5)$ & $1(0-5)$ \\
\hline \multicolumn{3}{|l|}{ HGS (kg) } \\
\hline Right & $17.8(8.8-28.1)$ & $18.5(9.3-31.7)$ \\
\hline Left & $16.3(6.0-28.2)$ & $15.6(6.2-30.7)$ \\
\hline
\end{tabular}

Values are presented as median (range).

BBS, Berg Balance Scale; FAC, Functional Ambulation Category; K-FRAIL, Korean version of the fatigue, resistance, ambulation, illnesses, and loss of weight; HGS, hand grip strength.

area and pathway length were correlated with BBS at 3 months ( $\mathrm{r}=-0.570, \mathrm{p}<0.001$ and $\mathrm{r}=-0.494, \mathrm{p}=0.002$, respectively) and 6 months $(\mathrm{r}=-0.694, \mathrm{p}<0.001$ and $\mathrm{r}=-0.692$, $\mathrm{p}<0.001$, respectively) (Table 2). Besides, BBS was correlated with FAC, walking ability by Koval, and K-FRAIL at 3 months $(r=0.634, p<0.001$ and $r=-0.566, p<0.001$ and $\mathrm{r}=-0.338, \mathrm{p}=0.038$, respectively), and correlated with FAC and walking ability by Koval at 6 months $(\mathrm{r}=0.764$, $\mathrm{p}<0.001$ and $\mathrm{r}=-0.603, \mathrm{p}=0.001$, respectively) (Table 3 ).

In terms of outcome prediction, the change in BBS was correlated with change in COP area $(\mathrm{r}=-0.577, \mathrm{p}=0.031)$, but not with change in COP length (Table 4). COP area

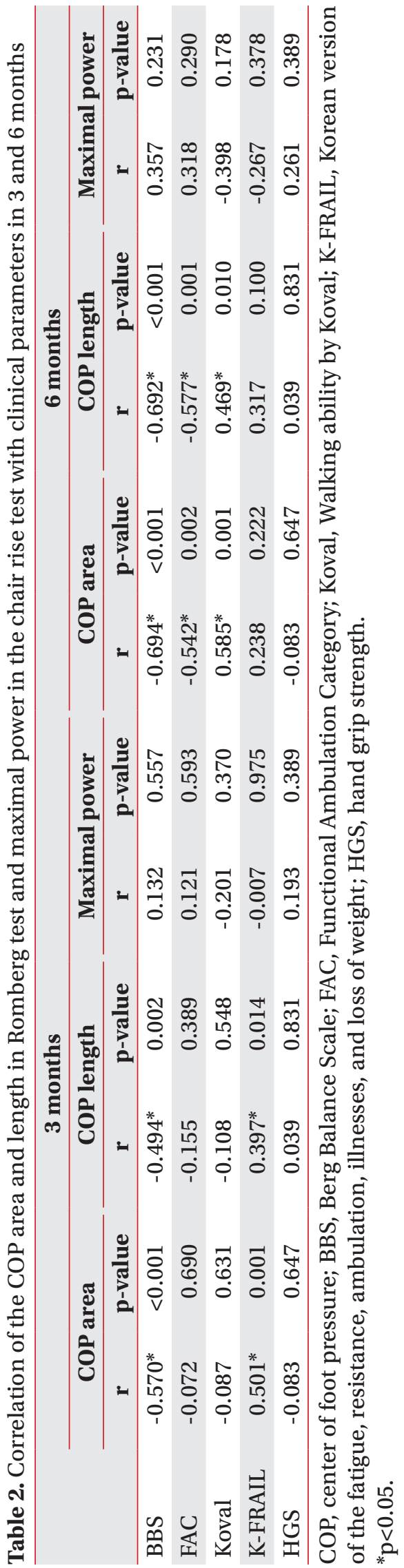


Table 3. Correlation of BBS with clinical parameters in 3 and 6 months

\begin{tabular}{lccccc}
\hline & \multicolumn{2}{c}{3 months } & & \multicolumn{2}{c}{ 6 months } \\
\cline { 2 - 3 } \cline { 5 - 6 } & $\mathbf{r}$ & p-value & & r & p-value \\
\hline FAC & $0.634^{*}$ & $<0.001$ & & $0.764^{*}$ & $<0.001$ \\
Koval & $-0.566^{*}$ & $<0.001$ & & $-0.603^{*}$ & 0.001 \\
K-FRAIL & $-0.338^{*}$ & 0.038 & & -0.304 & 0.116 \\
\hline
\end{tabular}

BBS, Berg Balance Scale; FAC, Functional Ambulation Category; Koval, Walking ability by Koval; K-FRAIL, Korean version of the fatigue, resistance, ambulation, illnesses, and loss of weight.

${ }^{*} \mathrm{p}<0.05$.

and pathway length were correlated with K-FRAIL at 3 months after hip fracture surgery $(\mathrm{r}=0.501, \mathrm{p}=0.001$ and $\mathrm{r}=0.397, \mathrm{p}=0.014$, respectively). The same COP variables showed correlations with FAC and walking ability by Koval at 6 months after surgery (area: $\mathrm{r}=-0.542, \mathrm{p}=0.002$ and $\mathrm{r}=0.585, \mathrm{p}=0.001$, respectively; length: $\mathrm{r}=-0.577$, $\mathrm{p}=0.001$ and $\mathrm{r}=0.469, \mathrm{p}=0.010$, respectively).

Maximal power during CRT had correlation with chair rise time at 3 and 6 months after hip fracture surgery ( $r=-$ $0.751, \mathrm{p}<0.001$ and $\mathrm{r}=-0.648, \mathrm{p}=0.004$, respectively) but not with BBS, FAC, walking ability by Koval, K-FRAIL, and HGS (Table 2).

\section{DISCUSSION}

BBS can be measured anywhere without special tools, and the test result is semi-quantitative with up to 56 points. Meanwhile, mechanography is complementary in that it is more quantitative and less time-consuming. In our study, both COP area and length measured by mechanography were significantly associated with BBS at 3 and 6 months. Even in patients with hip fracture, mechanography is proven to be useful for evaluating postural balance.

BBS has a ceiling effect of $22.5 \%$ for community-dwelling older people [14]. As this study was performed at 3 and 6 months, which is within the subacute stage after hip fracture surgery $[15,16]$, BBS would not be affected by the ceiling effect, resulting in significant correlation with mechanography. Further studies would be needed to determine the usefulness of mechanography to predict balance with a 1- to 2-year follow-up.

COP area and length in mechanography were corre-
Table 4. Correlation of changes in BBS with those in the COP area and length between 3 and 6 months after surgery

\begin{tabular}{lcc}
\hline & \multicolumn{2}{c}{$\Delta$ BBS } \\
\cline { 2 - 3 } & $\mathbf{r}$ & p-value \\
\hline$\Delta$ COP area & $-0.577^{*}$ & 0.031 \\
$\Delta$ COP length & -0.496 & 0.072 \\
\hline
\end{tabular}

BBS, Berg Balance Scale; COP, center of foot pressure. ${ }^{*} \mathrm{p}<0.05$.

lated with K-FRAIL at 3 months after hip fracture surgery, whereas the COP variables were correlated with FAC and walking ability by Koval at 6 months. In terms of immobilization and deconditioning, similar to frailty, skeletal muscle mass index correlated with BBS at 3 months after total hip replacement surgery in a previous study [17]. Moreover, lower-limb muscle weakness remained at 6 and 24 months after hip surgery, although gait and balance function recovered $[18,19]$. Thus, COP variables might be correlated with muscle function or frailty in the early subacute stage, whereas COP variables have correlation with ambulatory recovery in the late subacute period.

For an evaluation of functional improvement, we measured the relationship between the degree of change in BBS and the extent of COP length and area at 3 and 6 months after hip surgery. Changes in BBS and the extent of COP area were correlated, whereas changes in BBS and that of COP length revealed borderline significance. Lower COP length and area values would indicate better performance in terms of postural balance. However, previous studies on COP length and area difference showed no consensus regarding the variables related to change in postural control $[5,20]$. A larger sample size is needed to confirm that COP area is more useful when evaluating balance outcome.

Recently, COP displacement and velocity were shown to be related to postural balance [21]. However, it is not often applicable to measure COP displacement and velocity in patients with hip fractures due to hip pain and risk of falling. Moreover, BBS may not be sufficient to evaluate balance function, and additional balance parameters are required for the comprehensive assessment of postural balance [22]. Thus, it is encouraging that COP area and length have significant correlation with BBS. Quantitative mechanography can compensate for the limitation of 
BBS.

Since power is energy divided by time, maximal power and chair rise time should be related to each other, which was proven in this study. However, there was no significant association between lower-limb muscle power and other clinical parameters, including K-FRAIL and HGS.

There were several limitations to this study. First, not all patients could be evaluated because of their inability to stand without assistance at 3 months and there were drop-outs for a follow-up visit at 6 months after surgery. Second, a longer follow-up assessment with a larger sample size might be needed, although most patients regained premorbid or pre-fracture mobility function at 6 months after surgery. Third, dynamic COP parameters during the CRT would be more important than static COP variables, which is to be considered in future studies.

In conclusion, we demonstrated correlations between mechanography and clinical parameters at 3 and 6 months after surgery. The objective test with mechanography may be useful for quantitative and sensitive measurement of postural balance and lower limb muscle power in older patients surgically treated for hip fractures.

\section{CONFLICT OF INTEREST}

No potential conflicts of interest relevant to this article were reported.

\section{ACKNOWLEDGMENTS}

This research was supported by a grant by the Korea Health Technology R\&D Project through the Korea Health Industry Development Institute (KHIDI) funded by the Ministry of Health and Welfare, Republic of Korea (No. HC15C1189).

\section{AUTHOR CONTRIBUTION}

Conceptualization: Beom J, Ha YC, Lim JY. Methodology: Cho J, Kang SH, Kim DK, Seo KM. Formal analysis: Min TJ, Beom J. Funding acquisition: Ha YC. Project administration: Beom J, Ha YC, Lim JY. Writing - original draft: Min TJ. Writing - review and editing: Beom J. Approval of final manuscript: all authors.

\section{REFERENCES}

1. Lee D, Jo JY, Jung JS, Kim SJ. Prognostic factors predicting early recovery of pre-fracture functional mobility in elderly patients with hip fracture. Ann Rehabil Med 2014;38:827-35.

2. Santos GM, Souza AC, Virtuoso JF, Tavares GM, Mazo GZ. Predictive values at risk of falling in physically active and no active elderly with Berg Balance Scale. Rev Bras Fisioter 2011;15:95-101.

3. Radosavljevic N, Nikolic D, Lazovic M, Petronic I, Milicevic V, Radosavljevic Z, et al. Estimation of functional recovery in patients after hip fracture by Berg Balance Scale regarding the sex, age and comorbidity of participants. Geriatr Gerontol Int 2013;13:365-71.

4. Winter DA, Patla AE, Frank JS. Assessment of balance control in humans. Med Prog Technol 1990;16:31-51.

5. Li Z, Liang YY, Wang L, Sheng J, Ma SJ. Reliability and validity of center of pressure measures for balance assessment in older adults. J Phys Ther Sci 2016;28:13647.

6. Gray VL, Ivanova TD, Garland SJ. Reliability of center of pressure measures within and between sessions in individuals post-stroke and healthy controls. Gait Posture 2014;40:198-203.

7. Terra MB, Da Silva RA, Bueno MEB, Ferraz HB, Smaili SM. Center of pressure-based balance evaluation in individuals with Parkinson's disease: a reliability study. Physiother Theory Pract 2018:1-8.

8. Fried LP, Tangen CM, Walston J, Newman AB, Hirsch C, Gottdiener J, et al. Frailty in older adults: evidence for a phenotype. J Gerontol A Biol Sci Med Sci 2001;56: M146-56.

9. Morley JE, Malmstrom TK, Miller DK. A simple frailty questionnaire (FRAIL) predicts outcomes in middle aged African Americans. J Nutr Health Aging 2012;16: 601-8.

10. Jung HW, Yoo HJ, Park SY, Kim SW, Choi JY, Yoon SJ, et al. The Korean version of the FRAIL scale: clinical feasibility and validity of assessing the frailty status of Korean elderly. Korean J Intern Med 2016;31:594-600.

11. Baker D, Nance S, Moore M. The load that maximizes the average mechanical power output during jump squats in power-trained athletes. J Strength Cond Res 2001;15:92-7.

12. Smith WN, Del Rossi G, Adams JB, Abderlarahman 
KZ, Asfour SA, Roos BA, et al. Simple equations to predict concentric lower-body muscle power in older adults using the 30 -second chair-rise test: a pilot study. Clin Interv Aging 2010;5:173-80.

13. Koval KJ, Skovron ML, Aharonoff GB, Meadows SE, Zuckerman JD. Ambulatory ability after hip fracture: a prospective study in geriatric patients. Clin Orthop Relat Res 1995;(310):150-9.

14. Ban B, Sevsek F, Rugelj D. A comparison of the ceiling effect between Berg Balance Scale and Mini-BESTest in a group of balance trained community-dwelling older adults. Physiother Q 2017;25:3-9.

15. Ganz SB, Peterson MG, Russo PW, Guccione A. Functional recovery after hip fracture in the subacute setting. HSS J 2007;3:50-7.

16. Chong TW, Chan G, Feng L, Goh S, Hew A, Ng TP, et al. Integrated care pathway for hip fractures in a subacute rehabilitation setting. Ann Acad Med Singapore 2013;42:579-84.

17. Jo S, Park SB, Kim MJ, Kim T, Park KI, Sung J, et al. Comparison of balance, proprioception and skeletal muscle mass in total hip replacement patients with and without fracture: a pilot study. Ann Rehabil Med 2016;40:1064-70.

18. Rasch A, Dalen N, Berg HE. Muscle strength, gait, and balance in 20 patients with hip osteoarthritis followed for 2 years after THA. Acta Orthop 2010;81:183-8.

19. Judd DL, Dennis DA, Thomas AC, Wolfe P, Dayton MR, Stevens-Lapsley JE. Muscle strength and functional recovery during the first year after THA. Clin Orthop Relat Res 2014;472:654-64.

20. Palmieri RM, Ingersoll CD, Stone MB, Krause BA. Center-of-pressure parameters used in the assessment of postural control. J Sport Rehabil 2002;11:5166.

21. Thompson LA, Badache M, Cale S, Behera L, Zhang N. Balance performance as observed by center-of-pressure parameter characteristics in male soccer athletes and non-athletes. Sports (Basel) 2017;5.

22. Ambrose AF, Paul G, Hausdorff JM. Risk factors for falls among older adults: a review of the literature. Maturitas 2013;75:51-61. 